\title{
Managing the safety of police pursuits: a mixed method case study of the Metropolitan Police Service, London
}

\section{Introduction}

\subsection{Pursuit safety}

Pursuits are a risky activity and can lead to damage, injury and deaths of the police themselves, the pursued and other members of the public. When such injuries occur they also receive a high levels of scrutiny by the public, the media, the police and other bodies which monitor police activities (Independent Office for Police Conduct, 2018). These deaths and injuries can damage public confidence in police work. Research regarding police pursuits has revealed that although most pursuits were conducted without incident, many pursuits were initiated for relatively minor offences (largely traffic offences). Best and Eves (2005) carried out an in-depth analysis of 64 pursuits which led to 71 deaths in the UK 1998-2001. They concluded that police officers did not sufficiently consider the risks to their own safety or that of the general public. They also concluded that 'proportionality' was not considered in responding to pursuits where the suspect had' failed to stop' on request. Similarly, Hoffmann and Mazerolle (2005) showed that of the 630 pursuits in Queensland, Australia across a fiveyear period half were initiated for traffic offences and $25 \%$ were initiated for stolen cars. Of all the pursuits nearly a third involved a collision, $11 \%$ were injury collisions and 11 people lost their lives. They argued that the nature of the offences did not justify a pursuit and that more restrictive policies should be adopted. Moreover, analysis of police data on the number of casualties involved in pursuits has led many researchers to conclude that the police need to conduct risk assessments before they pursue and that these need to be underpinned through training (Chu, 2016).

From interviews with police pursuit drivers Broome (2013) characterised their psychological and cognitive experiences during pursuits. He identified internal pressures related to performance anxiety, a focus on the outcome (i.e. apprehending the fleeing suspect) and perceived consequences in terms of success or failure. He argued that pursuit management needs to consider factors such as the driver's emotional investment, their focus, their ability to dynamically assess risk and communicate under pressure. He also argued that it was important for drivers to make sense of the experience afterwards.

Psychological factors may also influence the behaviour of fleeing suspects. Alpert and Lum (2014) identified that most pursuits in the US occurred because the suspects were frightened of getting caught for minor offences and would have slowed done and driven more cautiously if they had felt safe from the police. They cite evidence (Alpert,1997) from Florida that more restrictive pursuits policy limited to 'serious felons only' did not lead to an increase in crime rates but led to an $82 \%$ decrease in pursuits. However, it is not clear what reduction in pursuit related injuries occurred, though arguably a decrease in the number of pursuits would decrease exposure to injury risk. They argued that good national and local quality data about pursuits is needed to produce an evidence-based pursuit policy. They called for more information about what factors contributed not just towards fatal pursuits (which receive intense public scrutiny) but also those with non-fatal outcomes so that a comparative analysis can be undertaken. He also argued that there should be more discussion about whether it was legitimate to initiate a pursuit in the first place. 


\subsection{Policy context for police pursuits in the UK}

The MPS comprises over 43,000 staff including 31,550 Police officers and 9,327 Police staff https://www.met.police.uk/police-forces/metropolitan-police/areas/about-us/about-themet/structure/, It covers 620 square miles and serves more than eight million people in London.

Since 2013, all police work in the UK, including pursuits, falls under the National Decision Model (NDM) https://www.app.college.police.uk/app-content/national-decision-model/. The NDM supports decision making by providing a framework in which 'decisions can be examined and challenged, both at the time and afterwards'. At the centre of the model is a code of ethics, which officers and staff must act in accordance with. The NDM recognises that in operational work police and staff have to make decisions in which they have to consider the balance of risk in often difficult and fast-moving situations. Police and staff are encouraged to use their discretion where appropriate if they can justify their decisions using the NDM. Current practice in the Metropolitan Police Service (MPS) is that pursuits are managed between the driver and a control room.

\subsection{Roles and responsibilities of police and staff involved in pursuit management}

The management of a pursuit involves police drivers in the pursuit who communicate with staff in a control room. Pursuits move from an initial to an advanced phase with drivers trained in each phase. Initial phase trained drivers follow the initial authorisation procedure and request tactical phase advanced drivers to assist and risk assess the circumstances of the pursuit, so that control staff can assign appropriate resources. Drivers in pursuits are usually accompanied by another officer (who is not necessarily a trained pursuit driver) to provide a dynamic risk assessment to the control room.

Tactical pursuit and containment (TPAC) phase trained advanced drivers are responsible for dynamic risk assessment and accurately communicating this to control room staff. They are responsible for seeking tactical engagement. The pursuit commander is an officer within one of the pursuing 'tactical phase' vehicles, responsible for executing tactics and maintaining communication during the pursuit.

In the control room, the supervisor has overall control of the pursuit, constantly risk assesses and ensures that tactical trained advanced drivers are assigned and identifies a pursuit commander. They have ultimate responsibility for decisions to authorise/discontinue pursuits and to seek tactical options. Communications staff are responsible for coordinating radio communications during the pursuit and approving initial and continued authorisation for the pursuit and constantly risk assess, based on information and intelligence received. They are responsible for assigning resources at the tactical phase. The tactics and containment advisor (TAC) is trained and experienced in tactical operations and advises on tactical options, providing operational support to police by monitoring their risk commentary.

\subsection{Aims and objectives}

Although serious incidents leading to major injuries are rare, it has been shown that focusing on them only touches the "tip of the iceberg" and near-miss data can provide much more information about potential problems (Jones et al., 1999). The aim of this study was to 
understand current non-fatal injury rates and learn from 'decision- making among police officers and staff managing public safety and policing of the roads. The objectives were to:

1. Describe the characteristics of pursuits and the proportion of pursuits that led to a non-fatal injury 2. Carry out qualitative research among police staff who have a role in managing operational risks involved in pursuits.

\section{Methodology}

\subsection{Operational definitions}

\subsubsection{Risk}

For this study the definition of risk refers to 'the likelihood that a person may be harmed or suffers adverse health effects if exposed to a hazard. ' as used by the UK regulator for health and safety at work, The Health and Safety Executive thttps://www.hsa.ie/eng/Topics/Hazards/.

\subsubsection{Pursuit}

Pursuits are generated by someone failing to stop for the police. The police can stop a vehicle for any reason. On request, drivers or riders have to pull over when it is safe to do so. It is an offence if the driver or rider fails to stop.

\subsection{Pursuit Data}

Data was provided by MPS in individual years for three calendar years: 2016-2018 This data included non-fatal injuries only. The custodian of the data is the MPS and the data isused for monitoring purposes and to learn from pursuits.

\subsubsection{Data coding.}

Data entry was done by the police using free text and this introduced considerable variability in the descriptions given for ostensibly similar events. For example, sometimes the term 'traffic offence' was used but other codes could also fall under this category such as excessive speed or suspected drink drive or no insurance. In consultation with the police, for the purposes of this study, all behaviours which could be described as traffic offences were grouped together. Another substantive issue with the database is that whilst all events were triggered by a fail to stop offence, fail to stop was often given as the reason for the pursuit but this gave little information about why they were requested the stop in the first place. The lack of consistency in coding and lack of explanation of pursuits described as 'fail to stop' were the key weaknesses of the data.

\subsubsection{Injury}

Non-fatal injuries were described in the database as either, slight, moderate, or severe. No clear definition of the different injury levels was given by the MPS. Clinically, injury is scored on an ordinal scale of 1 to 6 ( 1 indicating a minor injury and six being maximum). A casualty that sustains an injury with a score of three or higher is described as seriously injured (Department for Transport, 2016). This definition was not used by the police in the pursuit recording tool but MPS said that people who were hospitalised were regarded as severely injured. Given the lack of clarity on this definition, all injuries are considered together. The proportion of pursuits that led to an injury was used as an indicator of safety. 


\subsection{In-depth Interviews}

The topic guides were developed collaboratively between the author and MPS and covered the risk management of pursuits, availability of pre-emptive tactics, interaction between the various actors involved and the role of training. The research was approved by University College of London (UCL) Research Ethics Committee. To recruit MPS participants an advert was put out across the MPS by the police. The complete list of participants was provided to a field work company. Participants were then contacted by the fieldwork company to arrange a telephone interview. All interviews were audio recorded and transcribed. The interviews transcripts were analysed using Template Analysis (King, in Symon and Cassell (Eds), 2012) which is regarded as a pragmatic tool for applied policy research. The template was the topic guide of semi structured questions which can be regarded as a priori topics of interest. The aim of the qualitative research was not to quantify responses but reflect the ideas that arise in a guided conversation between researcher and participant. However, in order to help the reader a theme is defined as a response that occurred several times across transcripts i.e. by three or more participants. If ideas that emerged that seemed to be important to our understanding of pursuits but were only mentioned by one person this is stated throughout the analysis.

This initial template was developed by analysing the first three transcripts for each participant group and developing the template. Then the template was applied to the whole data set. Initially broad themes were identified under each section of the template and then more specific aspects of the theme were identified to represent the data in a hierarchical way. Relevant data were marked with a highlighter and from these marked text verbatim quotes were selected to exemplify the main ideas in the themes. Finally, once coding was completed the researcher interpreted the findings and developed a thematic map to show the relationships between themes (Braun and Clarke, 2006).

We interviewed 24 police staff involved in pursuit management: 12 drivers (identified as drivers 1-12), five tactical advisors who were in the control room (identified as tactical advisors 1-5), and seven control staff (identified as control staff 1-7). Whilst the necessary number of interviews required is a contested area, there is some agreement that around 6-12 interviews may be appropriate where the participants are relatively homogenous (Guest et al 2006). Our sample had shared characteristics in that all participants were working in the same organisation and were experienced in pursuit driving or pursuit management in the London context. Each participant group was asked similar questions about pursuit safety and the responses from each group are compared against each other under each of the a priori topics or under additional themes that emerged through the coding.

\section{Results}

\subsection{Participants characteristics}

Participant's characteristics are shown in Table 1

\section{Table 1}

Roles and experience of interview participants 


\begin{tabular}{|l|l|l|}
\hline Drivers* & Roles & $\begin{array}{l}\text { Experience in role (years or } \\
\text { months) }\end{array}$ \\
\hline 1 & Initial response & 6 \\
\hline 2 & Initial response & 9 \\
\hline 3 & TPAC & 12 \\
\hline 4 & Initial response & 8 \\
\hline 5 & Advanced & 12 \\
\hline 6 & Initial response & 5 \\
\hline 7 & Advanced & 8 \\
\hline 8 & Advanced & 8 \\
\hline 9 & Initial response & 7 \\
\hline 10 & Initial response & 17 \\
\hline 11 & TPAC & 19 \\
\hline 12 & Initial response & 8 \\
\hline Control room & & \\
\hline 1 & Supervisor & 10 \\
\hline 2 & Control room dispatcher & 16 \\
\hline 3 & Pursuit channel operator (radio) & 6 \\
\hline 4 & Pursuit channel operator (radio) & 3 \\
\hline 5 & Pursuit channel operator (radio) & 7 \\
\hline 6 & Pursuit channel operator (radio) & 5 \\
\hline 7 & Pursuit channel operator (radio) & 8 months \\
\hline TAC & & \\
\hline 1 & Tactical and containment advisor & 15 \\
\hline 2 & Tactical and containment advisor & 1.5 \\
\hline 3 & Tactical and containment advisor & 13 \\
\hline 4 & Tactical and containment advisor & 6 months \\
\hline 5 & Tactical and containment advisor & 7 months \\
\hline
\end{tabular}

*all had experience as an operator

\subsection{Police data on pursuits}

\subsubsection{Circumstances of pursuits}

On average the MPS data (Table 2) showed that most vehicles pursued were cars and the two main reasons given for the pursuit were, 'criminal activity' followed by 'failed to stop'. Whilst 'fail to stop' accounts for a quarter of all reasons given it does any detail about the trigger for the pursuit in the first place. Around a fifth (19\%) of all pursuits were discontinued. Of these, the main reasons given for discontinuing the pursuit were the disproportionate risk posed to the public,or because of unsatisfactory risk or tactics by police. When a pursuit was terminated this was mainly done by the control room supervisor. Arguably, most of the pursuits that occurred did not end up with a successful conclusion in terms of apprehending the subject with most discontinued or the subject being lost (on average $19 \%$ and $40 \%$ respectively). 


\subsubsection{Pursuits that involved non-fatal injury}

Between 2016-2018, there were 4468 pursuits recorded and 165 that involved an injury. The proportion that involved an injury was $3.7 \%$ (Table 3 )

Table 3

Proportion of pursuits that lead to a non- injury by type of person injured (2016-2018)

\begin{tabular}{|l|l|l|}
\hline Injured person & Number of injury pursuits & \% of all pursuits $(\mathrm{N}=4468)$ \\
\hline Police & 17 & 0.4 \\
\hline Subjects & 101 & 2.2 \\
\hline Public & 47 & 1.1 \\
\hline & 165 & $3.7 \%$ \\
\hline
\end{tabular}

Only $1 \%$ of pursuits involved an injury to a member of the public not involved in the pursuit.

\subsubsection{Details of injury involved MPS pursuit crashes}

On average 'criminal activity' accounted for nearly half of all reasons given for pursuits involving injury, whilst nearly a quarter were 'fail to stop' (Table 4). Drivers need to seek authorisation from the control staff in order to continue the pursuit. Most were authorised which probably reflects the greater incidence of the pursuits being caused by criminal activity. However, a sizeable minority had not been authorised by the control room staff. Whilst police can self-authorise, they need to justify their decision in line with NDM afterwards. Of pursuits where someone was injured, most involved a car at and $21 \%$ involved a motorcycle subject vehicle.

Table 4

\section{Injury involved pursuits by reason for the pursuit, authorisation, subject vehicle} involved

The quantitative data identified a number of issues to be explored in the interviews with different staff involved in pursuit management. These included factors police take into account in beginning a pursuit especially the fail to stop issue, the quality of risk commentaries, factors that the control staff take into account in the authorisation process and the checks and balances on risk including motivations, training and the role of the NDM.

\subsection{In-depth interviews}




\subsubsection{Factors affecting decisions to pursue}

There was a clear understanding about the risk factors that would increase the danger of a pursuit. Pursuits were regarded as a proportionate response for example for aggravated crime, dangerous driving but drivers acknowledged that pursuits were often spontaneous and triggered on a hunch:

For me, there's no hard and fast rule on when to and when not, if the intelligence is there to support it, I will. If the intelligence isn't there, but I have a gut feeling that it's necessary and it's hard to quantify what that is, then I will as well..... a copper's nose. (Driver Participant 10)

In these circumstances seeking evidence to corroborate such suspicions proved problematic. This type of pursuit was often caused by the driver/rider failing to stop on request and leading to an offence of failing to stop.

\subsubsection{The fail to stop issue}

This research revealed that from a control room perspective getting information from the police drivers was important to 'fathom out' the reason why the police wanted to stop the drivers in the first place. However, it was felt that this information was not always forthcoming. There was also a feeling that drivers reacted too quickly, without considering pre-emptive tactics or requesting further information from the control room and this generated many unnecessary pursuits:

...If an officer tells me he just failed to stop and they've got nothing else on this apart from their sort of sense that they think they're up to no good and I think that from what they've told me, I've got no further intelligence coming through or I'm not happy with the answers they're giving me about their speed, about the manner of driving because obviously they go through red lights, wrong side of the road, mount the pavement, like yesterday I had one in a busy town centre, he went through a red light which they didn't tell me straight away, he then mounted a pavement and this is all within seconds and went down the wrong side of a carriageway and as soon as he said that, I said terminate and this must have been a minute if that. (Control room participant 1)

There was also a tension within the control room where TAC advisors (normally police pursuit trained) were more likely to feel that a pursuit should be authorised on the grounds of 'fail to stop' whereas other staff were much more circumspect.

\subsubsection{The authorisation processes}

The authorisation process was perceived as difficult by the drivers because of the quality of radio communication, because of the dynamic between them and the control room and the lack of timely intelligence. Control room staff also acknowledged communication was comprised by poor sound on the radio channel which led to early pursuit termination decisions. Drivers expressed a 'disconnect' between patrols and the control room leading to difficulties in conveying risks and seeking authorisation which the drivers felt was in part because people in the control room were not experienced pursuit drivers which limited their understanding of making the right decision about the risk level. It was also felt that control room staff were risk averse, lacked courage and could not see the 'wider picture': 
If you've got the background and intelligence then it might help them make a judgement, but I don't think they often see the wider picture, I think they're scared of potential implications and they'd rather have evidence to back up their decision rather than err on the side of caution. (Driver Participant 6)

However, the 'remoteness' and 'objectivity' of people in the control room was perceived as something required to ensure the safety of pursuits:

The person that's responsible for the authorisation is not involved in the pursuit, they're monitoring the pursuit, so they've got a clear fresh mind, so they can see objectively. I think that's the best way to look at authorisations of a pursuit and that's to do it from an objective basis rather than being involved with the pursuit or involved in the investigation. (Driver Participant 9)

The TAC advisors (who were usually police trained to pursue) also felt that the process of authorisation was problematic due to lack of pursuit trained staff in the control room, and there was a feeling that control room staff put excessive pressure on the drivers/operators.

Compared to drivers, control room staff would prefer different tactical options and would not authorise a pursuit or would terminate it if they felt the justification by the driver was not acceptable. In this respect they felt that they protected the driver from themselves at a time when the driver's judgement may be clouded by the incident or intensity of it and any adverse consequences of being involved in a pursuit.

Moreover, the TAC advisors were perceived by control staff as a useful addition to the control room to help support decisions. TAC advisors had mixed views about whether a pursuit was a proportionate and felt that drivers were too quick to pursue and not enough was done to get the required intelligence in order to look at pre-emptive tactics to avoid a pursuit in the first place, whereas others felt the driver should be trusted.

\subsubsection{The importance of an experienced operator}

Drivers in pursuits are usually accompanied by another officer (who is not necessarily a trained pursuit driver) to provide a dynamic risk assessment to the control room. A dynamic risk assessment is where the operator observes and assesses the environment they are working in to identify hazards ( e.g. the behaviour of the subject vehicle, the presence of pedestrians, weather conditions etc. ) to make quick decisions about safety. They need to do this as a commentary to the control room so they can help evaluate the risk.

The importance of an experienced operator came through as a factor that affected the safety of pursuits. Drivers felt it was essential to have an operator who was also was an experienced driver who understood the risks and who could provide an accurate dynamic risk commentary to the control room. There was a view that the training for operators was inadequate and this was a hindrance to managing the risk of pursuits:

... a lot of the crew will get the operators who are low on experience, never done a pursuit, half of them don't drive, they have no idea where they are on the borough a lot of the time because they have other commitments and not learning as much as I used to, so the operator is passing information back is a huge hindrance. (Driver Participant 11)

Driver participants felt more should be done to train operators to help them provide better commentaries and this could be done by having to listen to live recordings of pursuits: 
Without a shadow of a doubt the training particularly to police operators is woefully inadequate. It is nothing like it should be. When I joined there used to be a radio operator's course ...... where you'd learn, a) how to speak on the radio, so you'd follow the $a, b, c$-accuracy, brevity, clarity, ..You'd learn how to relay the necessary information from what you are seeing to the information room, so that they can make an informed judgement about the pursuit, and that is not offered any more, I think they're given something like 10 minutes. (Driver Participant 8)

\subsubsection{Driver training}

There was a general feeling that driver training was minimal. It was felt that the safety of pursuits could be enhanced by

- Introducing refresher drivers skills course with advanced driver professional development

- Assessing the effectiveness of operator training on how to commentate in a pursuit or analyse risk correctly (potentially using a simulator)

- $\quad$ Training all the team e.g. control staff and drivers involved in pursuit management to understand dynamic risk assessment from a driver's perspective and to have a better understanding of the respective roles of the people in the control room

- Training more drivers in tactical containment to provide more pre-emptive options (with the acknowledgement that there was a lack of resources for this)

\subsubsection{The National Decision Model (NDM)}

The National Decision Model was viewed by participants as something that was engrained in their operational practices and worked almost at a subconscious level to shape their decision making. However, there were mixed views of the value of the NDM in managing pursuits. It was felt that the NDM could have a deterrent effect to undertaking pursuits because it gets people to think about how to minimise the risk of starting a pursuit in the first place:

I suppose it encourages us to continue evolving our decisions and rationalising what we're going to do and seeing if there is an alternative option. (Driver Participant 1)

It was also seen as a deterrent to pursuits because post pursuit, in the event of an adverse outcome, investigatory bodies were using it to hold the police to account. However, it was felt that the level of analysis is unrealistic and problematic especially as many of those undertaking the investigation had no experience of pursuit driving. It was said to be useful post incident to provide a standardised way of assessing risks. It was not felt to be helpful once a pursuit was underway in the most dynamic or fast-moving situations. It was felt that the NDM was not well understood by the 'rank and file' of the operational police officers within the MPS and more training was needed on how to use the NDM to pre-empt pursuits.

\subsubsection{Social, emotional and motivational factors which affect risk}

Factors that were viewed by participants to increase risk were getting fixated on stopping the pursued and bravado, whilst fear of personal repercussions tempered their approach to risk.

\section{Red mist}

Driver participants talked about a number of motivational factors which they felt could affect their ability to make rational decisions about the risks they were undertaking. A term that was frequently used was 'being sucked in' described as a total focus or fixation on stopping the 
pursued. The role of the operator was also seen as important to 're-set' the driver when they appeared fixated:

I had tunnel vision, I just focused on the car, the headlights, I don't remember seeing anything to the left or right or ahead of the vehicle and I didn't manage it at all. (Driver Participant 9)

Control room staff felt they could detect it and tried to manage it or would terminate a pursuit as a result. It was felt that there were 'layers of protection' against drivers being 'sucked in' or experiencing red mist:

.....you can hear that in the voice of the operator, i.e. they're screaming, or too panicky or it could be that through the transmissions we're hearing shouting or we're hearing something in the background that we're not happy with, then we can say that driver is getting too drawn in to it, we need to terminate for the safety of the officers, the safety of the public and the vehicle being pursued. (Control room tactical advisor Participant 4)

\section{Bravado}

Other motivational factors that affected a driver's fixation were talked about in terms of bravado and not wanting to lose face by losing the pursuit and letting the team down:

you are challenged to get results and it's not an emotional or personal thing, we're told to get results then sometimes that's what we've got to do.... and get a result for the team. (Driver Participant 12)

\section{Personal repercussions}

The potential personal repercussions (especially no legal protection) of an adverse outcome of a pursuit were 'top of mind' for participants and this clearly led drivers and control room staff to be more risk averse and this became part of the decision making on whether a pursuit was a proportionate response:

It's something I've thought about when I've had a vehicle make off and I think if I chase it and they crash and it goes wrong, then I'm in potentially a lot of trouble, so it does cross your mind there, if something goes wrong then you may be well hung out to dry.( Driver Participant 1)

\subsubsection{Two wheeled Crime}

Despite the vulnerability of subjects on motorised two wheels it was felt important to pursue them because often it would not be possible to get further information on them because the vehicles were stolen or being ridden on false plates. It was also felt that these types of crimes particularly affected public confidence in the police but were also fraught in terms of risk:

I do think motorcycles are riskier...... we can't just have someone come along nicking and riding up on a pavement and then driving off and the police can't do anything about it because they're too worried about what's going to happen if they get involved in a pursuit and it goes wrong. That will affect public confidence straight away (Control Room Participant 5)

\subsubsection{The role of air support in reducing risk}


34

Air support was viewed extremely positively by participants because it could take pressure off the drivers and gave a 'heads up' of prevailing conditions which could affect the risks involved in a pursuit:

It paints a better picture than someone shouting on the radio or trying to explain what's going on. It almost slows everything down for us.....it takes the pressure off everybody. The control room staff are a lot better knowing that vehicle is less likely to be lost because they've got an eye in the sky. The pursuing driver now knows that even if he loses sight of that vehicle, there is somebody above looking down. (Control room tactical advisor Participant 3)

\subsubsection{Learning from pursuits}

Participants felt that they rarely captured what they learned from pursuits (unless something had gone wrong causing death or injury) and there was minimal evaluation which they felt needed to change. It was also suggested that more could be done to learn from other countries on the problems they faced and how they addressed them. However, the acceptability and generalisability of international approaches would need to be fully assessed.

\subsubsection{The role of technology to pre-empt pursuits}

Participants felt technologies that exist now should have greater use such as tyre deflators but also more should be done to develop or work with technology that can remotely bring vehicles to a halt or track them via GPS to improve pre-emptive strategies.

\section{Discussion}

The recorded pursuit data showed that the MPS average proportion of pursuits that ended in a non-fatal injury was $3.7 \%$, with only $1 \%$ involving injury to a member of public not involved in the pursuit. This is also much lower than the proportion reported in other countries such as Australia where Hoffmann and Mazerolle report the figure to be around 11\% (2005),

Figure 1 shows a thematic map of factors that influence the management of risks in pursuits that emerged from the interviews with staff involved in pursuit management. 

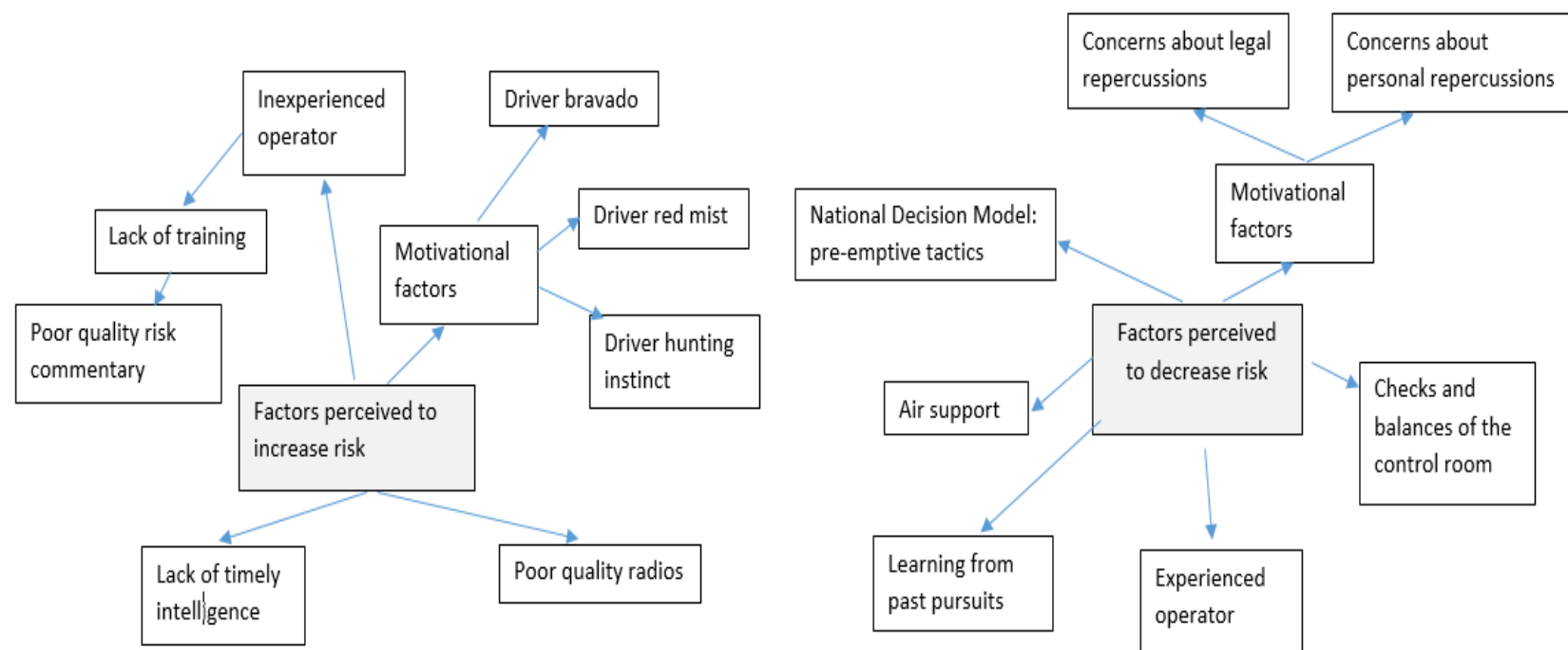

Factors perceived to influence the risks of pursuits

Figure 1 Thematic map of factors that participants perceived influenced the risks of pursuits

The interviews explored factors which participants felt reduced risk and the key themes related to this were that staff were acutely aware of the risks and the potential personal and legal repercussions of a pursuit that ends in injury which made them risk averse. This kind of criminalisation of unintentional error has been described in health care when errors by medical staff cause unintentional a harm to patients (Ameratunga, et al., 2019). The literature on this suggests that recording and understanding the circumstances of when things go wrong provides an opportunity to learn for practitioners to be reflective and avoid similar circumstances in the future.

This awareness of risk has been illustrated in previous qualitative research which described the meticulous accounts of risks experienced by police drivers and their understanding of the 'topography of risks' associated with pursuing a suspect (Dorn and Brown, 2003). The NDM has made staff more aware of their decision-making and whether a pursuit is a proportionate response. Interestingly, whilst the dynamic between the control room and the driver, although often criticised by the drivers, seemed to have provided checks and balances on pursuit risk 'protecting drivers from themselves'. The poor-quality risk commentary by operators also led to the control staff to stop a pursuit, which arguably reduces the risk of injury if the pursuit continued.

The role of air support was felt to reduce the risk of pursuits by taking the pressure of drivers and providing forward observation for the control room staff to predict the direction of the pursuit.

462 There were several factors which seemed to increase the risk of pursuits starting in the first nearly a quarter of all injury pursuits. Waddington (2010) described police as having a 
'hunting instinct' which can easily lead to emotional investment in a pursuit but he argued that a car is a weapon and this needed to be managed and controlled in the same way as the use of firearms is in an armed response. He argued that when travelling in a high-speed pursuit, police are 'virtually goaded' into increasing their speed and thereby pose a significant risk to innocent bystanders, concluding that there needs to be 'the same level of control as policies dealing with armed confrontations'. The drivers in this research talked about their motivations to pursue and how they acted on gut feeling.

They also described their tendency to fixate on the vehicle being pursued. Research has shown that police drivers compared to other 'control' drivers are more likely to be in a higher state of arousal, have greater visual sampling and searching when viewing hazardous scenarios in the context of a hazard perception experiment (Crundall et al, 2003). Arguably, the control room staff provided the checks and balances to these motivational factors which police drivers experience in pursuits.

More needs to be done by the police to understand why police made a request to stop in the first place. Reducing pursuits based on fail to stop could further reduce the risk of injury. The theme of unnecessary pursuits for fail to stop requests has been observed in previous research (e.g. Best and Eves, 2005). With respect to pursuing relatively, minor traffic offences it is a moot point whether this is justifiable given the strong correlation between traffic and criminal offences (Broughton, 2006). When police initiate a pursuit where someone is driving recklessly, they need to balance the potential harm of a pursuit against the harm of not pursuing i.e. the subject vehicle crashing and harming other members of the public.

Arguably, avoiding pursuits in the first place would be an ideal situation or finding other ways to track people under suspicion or known to have committed criminal behaviour using car-tagging technologies such as StarChase https://www.starchase.com/ (Gaither et al, 2017). This technology consists of an electronic tag in small projectile covered with a strong adhesive which contains a battery-operated GPS tracker and transmitter that is fired by compressed air from a small launcher on the front grille of a police car.

\section{Conclusions}

The MPS data suggest $\mathrm{s}$ that while rates of injury are low potentially they could be further lowered by reducing pursuits triggered for fail to stop requests or other minor traffic offences. In terms of policy and practice injury rates per 100 pursuits need to be monitored over time. More needs to be done to share learning from pursuit data. For example, this would allow police to see the risk associated with different types of offences for which they pursue and start a discussion about whether pursuing fail to stop offences is a proportionate response.

Police are highly aware of risk and the need to consider proportionality which is engrained through the NDM and tempered by their own motivations to avoid the intense scrutiny and accountability if injury occurs. The checks and balances provided by the control room staff and their caution in authorising pursuits seems to provide protection against drivers taking unjustified pursuits.

Training needs to be regularly refreshed in line with training for other operations which can involve lethal force such as firearms with special attention given to improving risk commentary training.

Technologies that track or immobilise a vehicle and curtail a pursuit need to be more widely available and in the future drones could be used as an alternative to helicopter deployment. A 
strength of the research is that it combined both quantitative data which provide a picture of the pursuit risks over the past three years with the perspectives of a range people involved in pursuits and is the first work to be carried out in this way in the UK. A weakness is that whilst the MPS is the largest force in England and Wales findings may not be generalizable to other forces that operate in different areas.

An area of further research would be to understand why people flee the police for relatively minor offences potentially creating a worse offence of failure to stop.

\section{Acknowledgements}

The author would like to acknowledge the support of Tristian Knight and Rich Lang from the Metropolitan Police Service for their support and advice and all the staff from the MPS that were interviewed to support this research. I would like to thank Further Afield for their excellent field work.

\section{Funding}

This work was funded by the Road Safety Trust.

\section{References}

Alpert, G.P., and Lum, C. (2014). Police Pursuit Driving: Policy and Research. Springer Briefs in Translational Criminology. https://DOI 10.1007/978-1-4939-0712-0_5

Ameratunga, R., Klonin, H., Vaughan, J., Merry, A.,, Cusack J.(2019) . Criminalisation of unintentional error in healthcare in the UK: a perspective from New Zealand BMJ 2019; 364 :1706

Best, D. and Eves, K. (2005). Why there are no lessons learned from road traffic incidents involving the police? Criminal Justice, 5(1): 37-53 DOI: 10.1177/1466802505050978

Braun, V. and Clarke, V. 2006. Using thematic analysis in psychology. Qualitative Research in Psychology, 3 (2): 83. doi:10.1191/1478088706qp063oa.

Broomé, R.E.(2013). The Lived-Experience of Leading a Successful Police Vehicle Pursuit: A Descriptive Phenomenological Psychological Inquiry. Journal of Phenomenological Psychology 44 (2013) 220-243 brill.com/jpp

\section{Broughton, J. (2006) The Correlation between Motoring Offences and Other Types of} Offence TRL Report 650, TRL. https://trl.co.uk/reports/TRL650

Chu, H.C. (2016). Risk factors for the severity of injury incurred in crashes involving on-duty police cars, Traffic Injury Prevention, 17:5, 495-501, https://doi.org/10.1080/15389588.2015.1109082

Crundall, D., Chapman, P., Phelps, N., Underwood, G. (2003) Eye movements and hazard perception in police pursuit and emergency response driving. J Exp Psychol Appl. 2003 Sep;9 (3):163-74.

Department for Transport (2016) Estimating clinically seriously injured (MAIS3+) road casualties in the UK https://www.google.com/url?sa=t\&rct=j\&q=\&esrc=s\&source=web\&cd=1\&ved=2ahUKEwja 25LC_pLoAhVUXsAKHcteD5kQFjAAegQIBhAB\&url=https\%3A\%2F\%2Fassets.publishin 
552 Dorn, L \& Brown, B. (2003). Making sense of invulnerability at work-a qualitative study of

553 police drivers. Safety Science, Vol 41, Issue 10, December 2003, Pages 837-859

554 Gaither, M., Gabriele, M., Andersen, N., Heayl, S., Hung, V. (2017). Pursuit Technology

555 Impact Assessment. National Institute of Justice

556 https://www.ncjrs.gov/App/Publications/abstract.aspx?ID=272715

557 Guest, G., Bunce, A., and Johnson L. (2006). How Many Interviews Are Enough? An

558 Experiment with Data Saturation and Variability. Field Methods.18 (1), page(s): 59-82 Issue

559 published. https://doi.org/10.1177/1525822X05279903

560 Hoffmann, G. and Mazerolle, P. (2005). Police pursuits in Queensland: research, review and

561 reform, Policing: An International Journal of Police Strategies \& Management, Vol. 28(3),

562 pp.530-545. https://doi.org/10.1108/13639510510614591

563 Independent Office for Police Conduct (2018). Deaths during or following police contact

564 England and Wales 2017 to 2018: time series tables 2004/05 to 2017/18.

565 https://www.gov.uk/government/organisations/independent-office-for-police-conduct

566 Jones et al., (1999), Journal of Loss Prevention in the Process Industries 12 (1): 59-67.

567 King, N. (1998). Template analysis. In G. Symon \& C. Cassell (Eds.). Qualitative methods

568 and analysis in organizational research: A practical guide (p. 118-134). Sage Publications

569 Ltd.

570 Waddington P. A. J. (2010). Police Pursuits: A Case Study of 'Critical Friendship'? Policing:

571 A Journal of Policy and Practice, Volume 4, Issue 2, Pages 119-126,

572 https://doi.org/10.1093/police/pap057

573

574

575

576

577

578

579

580

581 